\title{
‘Wallpaper paste sign’ of mucinous breast carcinoma
}

\author{
Muhammad Asad Parvaiz, Brian Isgar, Nedra Aluwihare
}

\begin{abstract}
Introduction: Mucinous carcinoma of the breast is an uncommon disease, characterized by a large amount of mucin production. Histologically, it is classified into two subgroups - pure type and mixed type. It usually affects postmenopausal women and is commonly associated with good prognosis. Case Report: We present a case of a 53-year-old female with a palpable breast lump which was clinically as well as radiologically suspicious of breast cancer. A free hand needle core biopsy was carried out. The biopsy material retrieved had a distinctive gross appearance, with soft, gelatinous consistency and a glistening clear surface. On this typical macroscopic appearance, a diagnosis of 'mucinous breast carcinoma' was made, which was subsequently confirmed on histological examination. The typical gross appearance of specimen on needle core biopsy is similar to the appearance of wallpaper paste; hence we describe it as 'wallpaper paste sign'. Conclusion: The hallmark of mucinous carcinoma is extracellular mucin production that gives it a typical glistening macroscopic appearance. Keeping in mind the 'wallpaper paste sign' we describe, mucinous breast carcinoma can be
\end{abstract}

Muhammad Asad Parvaiz ${ }^{1}$, Brian Isgar ${ }^{2}$, Nedra Aluwihare ${ }^{3}$ Affiliations: ${ }^{1}$ Specialty Doctor, Department of Breast Surgery, The Royal Wolverhampton NHS Trust, Wolverhampton, WV10 0QP, UK; ${ }^{2}$ Consultant Surgeon, Department of Breast Surgery, The Royal Wolverhampton NHS Trust, Wolverhampton, WV10 0QP, UK; ${ }^{3}$ Consultant Histopathologist, Department of Histopathology, The Royal Wolverhampton NHS Trust, Wolverhampton, WV10 0QP, UK.

Corresponding Author: Muhammad Asad Parvaiz, Specialty Doctor, Department of Breast Surgery, The Royal Wolverhampton NHS Trust, Wolverhampton, WV10 0QP, UK; Ph: +44-1902-695978; E-mail: asad.parvaiz@nhs.net

Received: 22 January 2013

Accepted: 04 mAY 2013

Published: 01 October 2013 diagnosed on patient's first visit to the breast clinic on gross inspection of the needle core biopsy specimen.

Keywords: Mucinous breast carcinoma, Wallpaper paste sign, Extracellular mucin, Core biopsy

$* * * * * * * * *$

Parvaiz MA, Isgar B, Aluwihare N. 'Wallpaper paste sign' of mucinous breast carcinoma. International Journal of Case Reports and Images 2013;4(10):551-553.

$* * * * * * * * *$

doi:10.5348/ijcri-2013-10-377-CR-6

\section{INTRODUCTION}

Mucinous carcinoma of the breast is not a common disease and its incidence has been reported to range from $1-6 \%$ of all primary breast cancers [1-4]. It is characterized by a large amount of mucin production and in general, defined as having a mucinous component of $50 \%$ or more $[5,6]$. Histologically, it is classified into two subgroups- pure type and mixed type [7, 8].

The pure type is the classical type composed entirely of mucinous carcinoma and can be further subdivided into cellular and hypo-cellular variants based on the degree of cellularity. When the mucinous component is mixed with another tumor type, this is the condition of mixed mucinous cancer which is most commonly ductal type (mucinous-ductal).

Immunohistochemistry is not generally required for the confirmation of mucinous breast carcinoma. However, a notable proportion of lesions especially the cellular variant of pure mucinous carcinoma demonstrate neuroendocrine differentiation. These tumors are immunoreactive for chromogranin and synaptophysin [5, 9]. Typically, mucinous carcinoma is estrogen receptor positive. 


\section{CASE REPORT}

A 53-year-old female was presented to the breast clinic with a palpable breast lump. Clinically, the lump was suspicious of breast cancer. Mammogram and ultrasound scan also confirmed the suspicious nature of the lump. A free hand needle core biopsy was carried out in the one-stop triple assessment clinic on index presentation. The core biopsy material retrieved had a distinctive gross appearance, with soft, gelatinous consistency and a glistening clear almost see-through surface (Figure 1). On this typical macroscopic appearance, a diagnosis of 'mucinous breast carcinoma' was made, which was subsequently confirmed on microscopic histological examination. The hallmark of mucinous carcinoma is extracellular mucin production, the extent of which varies from tumor to tumor. Typically, mucinous cancer cells in small clusters, sheets, or papillary configurations are dispersed within pools of extracellular mucin (Figure 2).

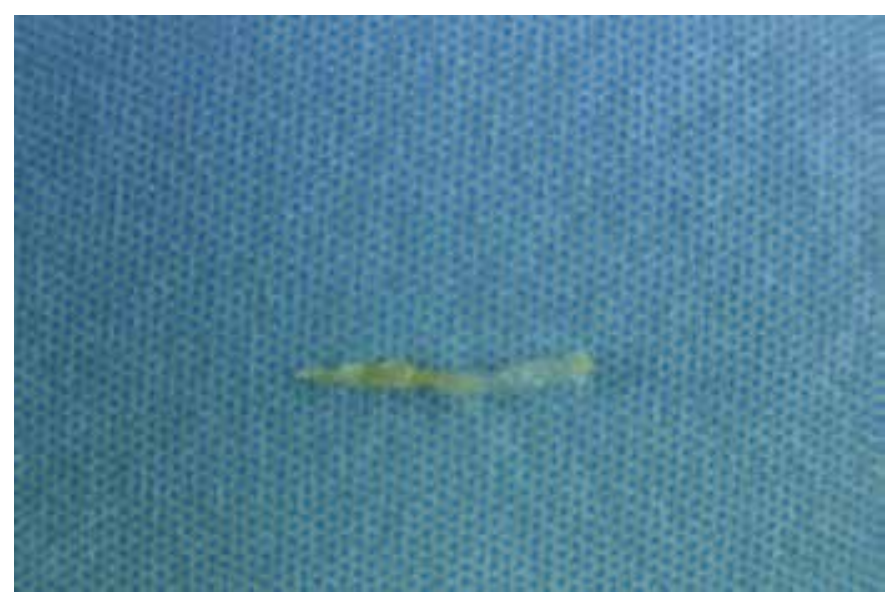

Figure 1: Wallpaper paste sign of macroscopic appearance of mucinous breast carcinoma on needle core biopsy.

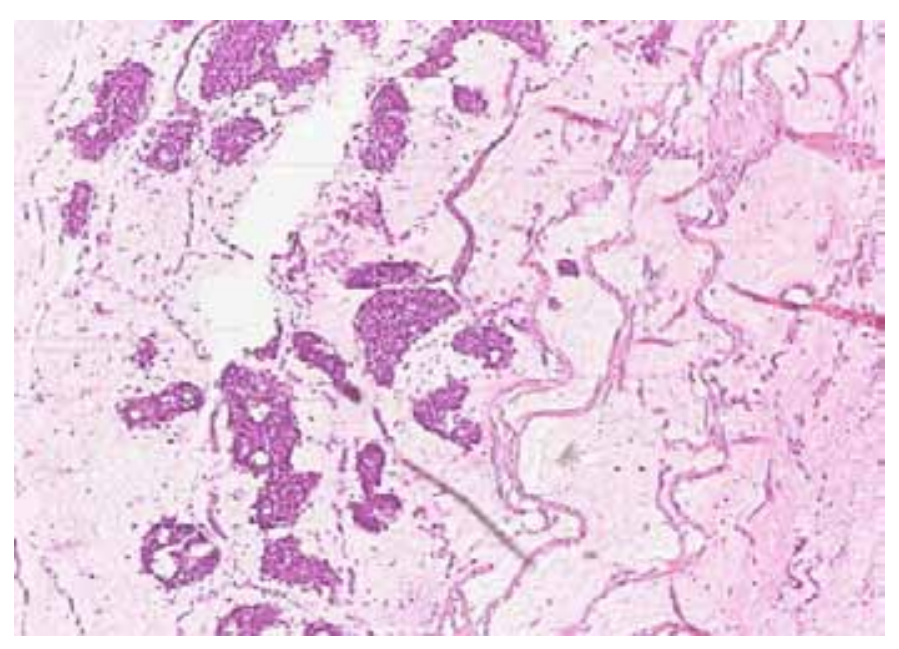

Figure 2: Histological appearance of mucinous breast carcinoma; lakes of lightly staining mucin with islands of neoplastic cells floating (H\&E stain, x2OO).

\section{DISCUSSION}

Mucinous carcinoma of the breast usually occurs in postmenopausal women. Median age of diagnosis is 71 years (range $25-85$ years) $[4,6]$. It shows more favorable clinicopathological characteristics, such as lower incidence of nodal metastasis, higher expression of estrogen and progesterone receptors and differentiated grade $[2,6,10,11]$.

The typical gross appearance of the mucinous breast carcinoma is a well-defined cystic mass, consisting of abundant transparent to bloodstained mucin as well as whitish solid parts [12]. This gelatinous and glistening gross appearance of mucinous breast carcinoma on needle core biopsy is similar to the appearance of wallpaper paste used to stick the wallpaper to a wall. We describe it as 'wallpaper paste sign' of mucinous breast carcinoma on needle core biopsy because of this similarity in appearances. This sign has been successfully reproducible in our practice over a period of time. Whenever such needle core biopsy appearance is retrieved in the clinic, we write 'positive wallpaper paste sign- mucinous breast carcinoma?' on the histology request form. This has always been confirmed on the microscopic analysis and immunohistochemistry when required.

Mucinous breast carcinoma is associated with a relatively favorable prognosis with a 5 -year breast cancer specific survival rate of $94 \%$. Although slowly decreasing with time, 10, 15 and 20 years survival rates are $89 \%, 85 \%$ and $81 \%$, respectively compared to $82 \%$ ( 5 year), $72 \%$ (10 year), 66\% (15 year) and 62\% (20 year) for invasive ductal carcinoma $\left[1,6,13^{-15}\right]$.

\section{CONCLUSION}

Mucinous carcinoma is relatively rare type of breast cancer and it can be diagnosed on patient's first visit to the breast clinic on gross inspection of the needle core biopsy specimen.

$* * * * * * * * *$

\section{Author Contributions}

Muhammad Asad Parvaiz - Substantial contributions to conception and design, Acquisition of data, Analysis and interpretation of data, Drafting the article, Revising it critically for important intellectual content, Final approval of the version to be published

Brian Isgar - Substantial contributions to conception and design, Revising it critically for important intellectual content, Final approval of the version to be published Nedra Aluwihare - Substantial contributions to conception and design, Drafting the article, Revising it critically for important intellectual content, Final approval of the version to be published

\section{Guarantor}


The corresponding author is the guarantor of submission.

\section{Conflict of Interest}

Authors declare no conflict of interest.

\section{Copyright}

(C) Muhammad Asad Parvaiz et al. 2012; This article is distributed under the terms of Creative Commons attribution 3.0 License which permits unrestricted use, distribution and reproduction in any means provided the original authors and original publisher are properly credited. (Please see www.ijcasereportsandimages.com/ copyright-policy.php for more information.)

\section{REFERENCES}

1. Louwman MW, Vriezen M, van Beek MW, NoltheniusPuylaert MC, van der Sangen MJ, Roumen RM, Kiemeney LA, Coebergh JW. Uncommon breast tumors in perspective: incidence, treatment and survival in the Netherlands. Int $\mathrm{J}$ Cancer. 2007;121:127-135.

2. Andre S, Cunha F, Bernardo M, Meneses e Sousa J, Cortez F, Soares J. Mucinous carcinoma of the breast: a pathologic study of 82 cases. J Surg Oncol. 1995;58:162-167.

3. Li CI, Uribe DJ, Daling JR. Clinical characteristics of different 62 histologic types of breast cancer. $\mathrm{Br} \mathrm{J}$ Cancer. 2005;93:1046-1052.

4. Diab SG, Clark GM, Osborne CK, Libby A, Allred DC, Elledge RM. Tumor characteristics and clinical outcome of tubular and mucinous breast carcinomas. J Clin Oncol. 1999;17:1442-1448.

5. Tan PH, Tse GM, Bay BH. Mucinous breast lesions: diagnostic challenges. J Clin Pathol. 2008;61:11-19.
6. Di Saverio S, Gutierrez J, Avisar E. A retrospective review with long term follow up of 11,400 cases of pure mucinous breast carcinoma. Breast Cancer Res Treat. 2008;111:541-547.

7. Silverberg SG, Kay S, Chitale AR, Levitt SH. Colloid carcinoma of the breast. Am J Clin Pathol.1971;55:355-363.

8. Dogan E, Aksoy S, Dizdar O, Arslan C, Dede DS, Ozisik Y, Altundag K. Pure mucinous carcinoma of the breast: a single center experience. J Buon. 2011;16(3):565-7.

9. Capella C, Eusebi V, Mann B, Azzopardi JG. Endocrine differentiation in mucoid carcinoma of the breast. Histopath. 1980;4:613-30.

10. Komenaka IK, El-Tamer MB, Troxel A, Hamele-Bena D, Joseph KA, Horowitz E, Ditkoff BA, Schnabel FR. Pure mucinous carcinoma of the breast. Am J Surg. 2004;187:528-32.

11. Barkley CR, Ligibel JA, Wong JS, Lipsitz S, Smith BL, Golshan M. Mucinous breast carcinoma: a large contemporary series. Am J Surg. 2008 Oct;196(4):549-51.

12. Chen WY, Chen CS, Chen HC, Hung YJ, Chu JS. Mucinous cystadenocarcinoma of the breast coexisting with infiltrating ductal carcinoma. Pathol Int. 2004;54(10):781-6.

13. Page DL. Special types of invasive breast cancer, with clinical implications. Am J Surg Pathol.2003;27:832-835.

14. Park S, Koo J, Kim JH, Yang WI, Park BW, Lee KS. Clinicopathological characteristics of mucinous carcinoma of the breast in Korea: comparison with invasive ductal carcinoma-not otherwise specified. 92 J Korean Med Sci. 2010;25(3):361-8.

15. Hanagiri T, Ono K, Baba T, So T, Yamasaki M, Nagata Y, Uramoto H, Takenoyama M, Yasumoto $\mathrm{K}$. Clinicopathologic characteristics of mucinous carcinoma of the breast. Int Surg. 2010;95(2):126-9.
Access full text article on other devices

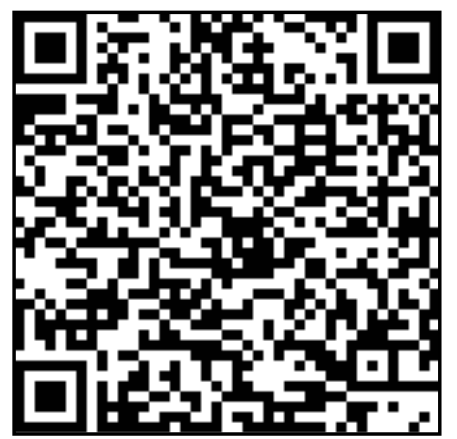

Access PDF of article on other devices

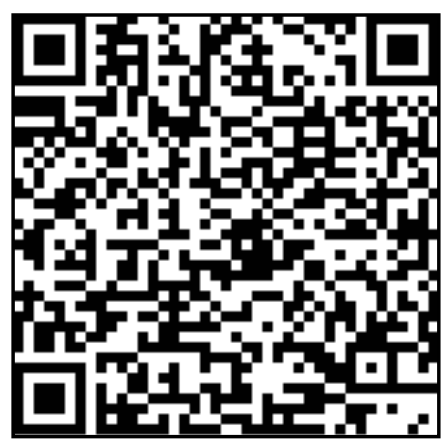

